Article

\title{
Care, Indifference and Anxiety-Attitudes toward Location Data in Everyday Life
}

\author{
Michal Rzeszewski ${ }^{1, *}$ (1) and Piotr Luczys ${ }^{2}$ \\ 1 Faculty of Geographical and Geological Sciences, Adam Mickiewicz University, Krygowskiego 10, \\ 61-680 Poznan, Poland \\ 2 Institute of Sociology, Adam Mickiewicz University, Szamarzewskiego 89, 60-568 Poznan, Poland; \\ lurys-granat@wp.pl \\ * Correspondence: mrz@amu.edu.pl; Tel.: +48-602-642-123
}

Received: 6 September 2018; Accepted: 21 September 2018; Published: 23 September 2018

\begin{abstract}
Modern mobile devices are replete with advanced sensors that expand the array of possible methods of locating users. This can be used as a tool to gather and use spatial information, but it also brings with it the specter of "geosurveillance" in which the "location" becomes a product in itself. In the realm of software developers, space/place has been reduced and discretized to a set of coordinates, devoid of human experiences and meanings. To function in such digitally augmented realities, people need to adopt specific attitudes, often marked with anxiety. We explored attitudes toward location data collection practices using qualitative questionnaire surveys $(n=280)$ from Poznan and Edinburgh. The prevailing attitude that we identified is neutral with a strong undertone of resignation-surrendering personal location is viewed as a form of digital currency. A smaller number of people had stronger, emotional views, either very positive or very negative, based on uncritical technological enthusiasm or fear of privacy violation. Such a wide spectrum of attitudes is not only produced by interaction with technology but can also be a result of different values associated with space and place itself. Those attitudes can bring additional bias into spatial datasets that is not related to demographics.
\end{abstract}

Keywords: location-based services; geosurveillance; social media; location data; geoprivacy; attitude; geolocation; geotagging

\section{Introduction and Literature Review}

In a relatively short span of time, location data have become an important part of our everyday life. Advances in information and communication technologies (ICT) have introduced the possibility of identifying one's position with almost pin-point accuracy with a simple mobile app. A large part of the world's population has a high precision localization instrument with them almost at all times-a smartphone or a similar mobile device. These devices are saturated with sensors that expand the array of possible methods for locating users: from GPS (Global Positioning System) chipsets to analysis of battery usage. While these technologies are often perceived positively, as a tool to gather spatial information and promote spatial knowledge [1,2], it is also clear that, simultaneously, they evoke the specter of surveillance, which in this particular incarnation has been dubbed "geosurveillance" [3,4]. As individuals, we produce a constant stream of information that can be used to observe and predict our spatial behavior. People have become human sensors [1] but often without their consent or knowledge. Fisher and Dobson [5] perceived this as a very real threat and a challenge to the ethics of geographic information systems (GIS) and even saw the possibility of "geoslavery," with location-tracking technologies allowing "to control other individuals or groups of individuals" [6]. We have become our own data brokers, and we need to decide every time whether we 
wish to allow another shiny new mobile app to gather intimate data about our movements. It can be assumed that the decision of whether to permit "access to information about location" for a given piece of software is worth the price of privacy and is beyond the technical knowledge or interest of most users. The issue of privacy is increasingly complicated since it has become a network phenomenon [7]. Research by Abbas [8] showed that the amount of trust within a relationship determines people's willingness to give out location-but the problem is that those relationships are no longer easily identifiable. As a result, more often than not, users decide to give the permissions they are asked for [9] and, in doing so, they are transformed into willing cogs in the geosurveillance machine [10]. The incentives to opt-out, to boycott, to remove ourselves from this mechanism are very few and the frequent examples of data-leaks and shadowy practices of giants such as Uber and Facebook [11,12] strengthen the myth that in the world of big data everything is already in a database somewhere. At the same time as users produce (or rather just provide) data, they also consume part of the stream of geospatial information to fuel and inform their quotidian activities through location-based services (LBS) - which provide "geographically-oriented data and information services to users across mobile telecommunication networks" [13]. Services that use location data in a variety of applications are extremely popular among all mobile phone users [14] and have sparked a lively interest among GIS scientists and practitioners $[15,16]$. Apart from the technological issues and many possibilities for practical applications, the LBS research community also pays close attention to the societal implications of this technology $[17,18]$. The ability to locate ourselves and others, even strangers, is transforming our behavior [18] — even the way we interact in everyday situations [19]. This also means we experience the space and place itself differently and this new kind of spatial cognition has the potentially totalizing effect that can dominate the way we think about spatiality [20]. The ethical dilemmas of LBS are also numerous. Thirty-years ago, Roger Clarke coined the term "dataveillance" — "the systematic use of personal data systems in the investigation or monitoring of the actions or communications of one or more persons" [21] — which applied to personal location information becomes even more concerning. Michael and Michael [22] argue that easy access to location tracking technologies can even lead to a state of uberveillance. While this phenomenon is often associated with the increasing power of the State and various national agencies [23], this also empowers entities such as international corporations that are hard to control [24]. Clarke and Wigan [24] mention several dangers they associate with dataveillance and personal location disclosure: (1) psychological damage from disclosure of embarrassing behavior; (2) 'chilling effect' on non-conformist behavior; (3) profiling, suspicion-generation and manipulation of consumer behavior; (4) using location data as 'circumstantial evidence' for criminal cases; (5) enhanced visibility of behavior that allows for easier surveillance; (6) 'chilling effect' on voicing of unpopular opinion and participation in demonstrations, which can lead to a weaker democracy; (7) greater possibility of politically damaging disclosures; (8) real-life repression of the easily locatable and trackable individuals. In general, those ethical challenges can be considered within the framework proposed by Michael et al. [25], which consists of four dilemmas of privacy, accuracy, property, and accessibility. For a recent review of this issue, see the work of Abbas et al. [26]. Those threats, however, do not have a direct influence on how LBS is used. Services and apps that use location are perceived as pleasurable [27] or, even more serious, as an immanent part of social life [28]. Users are increasingly aware that they live in an omnopticon $[29,30]$, but they do not want to change their behavior [31]—although some mechanism to change this situation has been proposed—see [32].

As Thatcher [27] accurately notes, "location" has become a product in itself, something that can be stored and exchanged [33]. In the realm of apps and software developers, it has been more than often reduced and discretized to a set of coordinates, devoid of the experiences and meanings associated with the space and places of daily life. Such an understood location can be linked to unique personal identifiers and then in this quantified state used as a basis for various services, such as navigation, mobile commerce, entertainment or social media. In this form, location is much more susceptible to algorithmic sorting and processing. With this simplification, developers may avoid problems with the 
digital representation of the world that has been the subject of critical cartography and critical GIS inquiry in the fields of digital and internet mapping [34-41].

Location has become a valuable commodity that is sought after by large corporations as a powerful tool for shaping consumptive behavior [42] —as the recent example of the acquisition by Snap Inc. of "Placed" has shown [43]. This process reduces and redacts the world as it is seen by force of capital. Experiences are homogenized and outliers removed. What is left are big sets of spatial data with their own sets of problems that generate a large body of critical literature.

By allowing their location and associated experiences to become data points in privately owned software systems such as Yelp or Tinder, people subject themselves to "data colonialism" [44]. These colonial practices are aimed at the commodification of location data-a new area for investment, ready to create value through the basic capitalist process of accumulation by dispossession. This process is almost natural to the user and clicking "Yes" on an End User License Agreement (EULA) without reading it is common behavior [45]—the eventual benefits of boycotting by choosing "No" are minimal for a single person and the possible negative consequences are perceived to be much worse, with anxieties driven by Fear of Missing Out (FoMO) [46].

We consciously or unconsciously take part in the location-based culture that can be seen as "the ultimate materialization of Foucault's [47] theories of subjection" [10]. Dobson and Fisher [48] see this as a kind of new panopticon ("panopticon III") in which, for the first time, benefits are available both for the watchers and those that are being watched. We allow the creation of the big spatial datasets that are the result of the big "data grab" [49] for a multitude of reasons, seemingly without much thought and hesitation and even when users are not visibly compensated for relinquishing their location privacy [50]. Behavior such as this is consistent with the way software functions are perceived-they hide from our conscious thoughts, retreating into the background hum of the ever-present technology and become visible only in its brief moments of failure [51,52]. Only when the purpose-oriented nature of the algorithms is exposed, do users see this as something bad [53]. And there is no doubt that these digital technologies are increasingly permeating our everyday lives. As people living in spaces constantly augmented by whole array of new technologies, we create and adopt strategies to cope with the ever-changing world. Location-based services and location data production and consumption in general can be seen as one such technology.

We assume in the paper that strategies for dealing with the intrusion or introduction of new technology are based on individual attitudes. In our research, we use the term "attitude" as one of our main vehicles of explanation. Although it has been defined and re-defined a myriad times, we have opted to use one of the three classical component definitions [54] (p. 6). We, therefore, understood attitudes as "... enduring systems of positive or negative evaluations, emotional feelings and pro or con actions tendencies with respect to social objects" [55] (p. 139). Such defined attitudes can, in our view, be used to describe the complex ways in which people perceive, feel about, and use location-based technologies. People's feelings toward the gathering of location data have been described before, for example, by Crawford [56] as 'surveillant anxiety' and by Leszczynski [57] as 'anxieties of control' - we discuss those propositions in the light of our results. The main aim of our research and the purpose of this study is to further explore the spectrum of human attitudes toward location data collection and production. We see these attitudes as signs of location-based culture and we want to investigate its formation. Specifically, we seek answers for the following research questions:

- RQ1: How much knowledge about location-based services and technologies do ordinary people have or rather think they have?

- RQ2: What is the main sentiment about the location data grab?

- RQ3: What are the attitudes that people adopt to cope with the pervasiveness of location-based technology? 


\section{Materials and Methods}

The research was carried out according to a geographical and sociological theoretical model [58-60]. The research design can be seen in Figure 1 and it is described in detail in this section of the paper. For the purpose of clarity, the diagram also consists of the project stages that are currently in progress and are the direct followup for the study described here. The first part of the project was the construction of an off-line questionnaire survey with 16 detailed research questions and 5 metrics questions (see the link to the Supplementary Materials 1 at the end of the paper). Validity of the questionnaire was established using only face validity and separate evaluation by both authors [61]. The survey consisted of three kinds of questions, different in both form and content: Open-familiarity with own mobile device, visual identification of activities associated with smartphone use, definitions of LBS and augmented reality (AR) and reflections on the digital divide; Multiple choice-LBS and AR use in everyday life; Single choice-filter or contingency questions that separated people with different experiences.

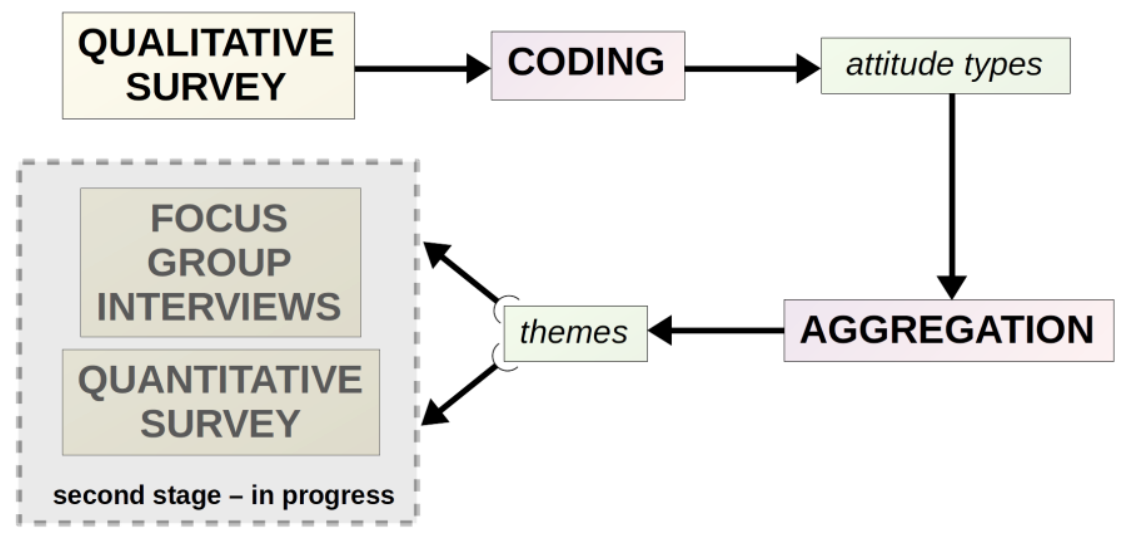

Figure 1. Research design for the project. Grayed out stages are in progress and are not described in this paper.

In the questionnaire, we have asked a series of questions about the respondents' smartphone model and its strong and weak sides, the activities related to mobile devices (navigation, games, SMS etc.), knowledge of terms related to LBS and AR, as well as the usage of those technologies in everyday life. The latter category of questions was expanded by detailed queries about installed apps, usage contexts and basis for granting geolocation privileges to mobile software. At the end, we asked our respondents to explain the digital exclusion issue and to indicate certain categories of people that are excluded. Images associated with those questions were used to inspire a discussion with their non-stereotypical content-with every person pictured using a mobile device.

We gathered 278 responses from among sociology and geography (including geoinformatics) students at Adam Mickiewicz University in Poznan and the School of Social and Political Science, University of Edinburgh. This consisted of 30-35\% Polish geography students and 60-65\% Polish sociology students and approximately $30 \%$ for both groups at the University of Edinburgh. In the sample as a whole, there was an over-representation of sociology students $(71.5 \%)$, women $(70.1 \%)$, and respondents from Poland (78.9\%)—detailed respondents' characteristics can be seen in Figure 2. It must be noted that our survey was designed to gather information about the diversity of the characteristics among the population and as such it was a qualitative survey [62]. This method is suitable for the exploratory phase of research. Therefore, representativeness was not the main aim for our sample population-we rather opted for as many responses as possible, even when it deepened the bias. A student population is obviously biased in some characteristics and this limits the possibility of drawing general conclusions. Our respondents were probably more skilled and more accustomed to using mobile services and smartphones than the average city dweller. However, this student population can provide us with a glimpse into the everyday life and habits of a casual technology user. 
By splitting the survey between geography and sociology students, we wanted to capture both more technologically oriented and socially involved individuals.
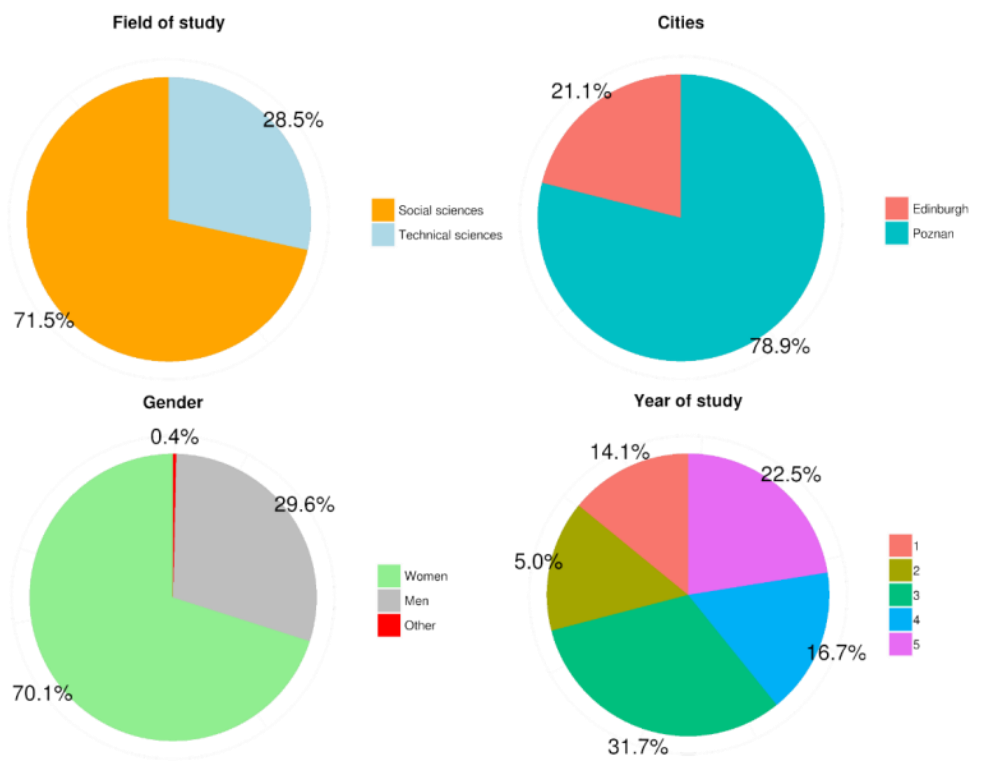

Figure 2. Respondents' characteristics.

In the next step, we grouped responses according to three dimensions, defined as follows:

- Knowledge - everyday use of LBS and knowledge of the possibilities of use and the underlying technology;

- Emotions-emotional attitude toward LBS and technology in general;

- Reflection-reflection about the societal implications of LBS and technology in general.

Each response was then evaluated in each dimension according to the criteria detailed in Table 1. For knowledge and emotion, we used three levels $(\mathrm{Y}, 0, \mathrm{~N})$ while reflection was treated as a binary $(\mathrm{Y}, \mathrm{N})$, which gave us 18 possible outcomes. We also added the possibility of N/A code for each dimension, when it was impossible to determine the level-this happened when responses to a given set of questions were impossible to decipher, incomplete, or entirely missing. This increased the number of possible types to 48 .

Table 1. Detailed coding criteria in three dimensions adopted in the study.

\begin{tabular}{|c|c|c|c|c|}
\hline \multirow{2}{*}{ Dimension } & \multirow{2}{*}{ Coding Criteria } & \multicolumn{3}{|c|}{ Levels and Interpretation } \\
\hline & & $\mathbf{Y}$ & 0 & $\mathbf{N}$ \\
\hline Knowledge & $\begin{array}{l}\text { usage and knowledge about } \\
\text { geotagging/geolocation, AR and } \\
\text { GPS; awareness of pervasiveness of } \\
\text { LBS; effortless use of technical } \\
\text { terminology (questions: } 1-6,9-11,13 \text { ) }\end{array}$ & $\begin{array}{c}\text { effortless use of } \\
\text { technology and } \\
\text { extensive knowledge }\end{array}$ & $\begin{array}{l}\text { effortless use } \\
\text { without knowledge } \\
\text { or extensive } \\
\text { knowledge with } \\
\text { limited use }\end{array}$ & $\begin{array}{c}\text { mechanical use of } \\
\text { technology and } \\
\text { lack of } \\
\text { understanding }\end{array}$ \\
\hline Emotions & $\begin{array}{l}\text { conscious permission or refusal to } \\
\text { give away personal location; } \\
\text { attitude and sentiment in open } \\
\text { questions-e.g., "useful" vs. } \\
\text { "invigilation" and "practical" vs. } \\
\text { "lacking privacy" } \\
\text { (questions: } 7-10,12,14, \text { ) }\end{array}$ & $\begin{array}{l}\text { enthusiastic adoption } \\
\text { of technology; } \\
\text { technology has only } \\
\text { positive influence; give } \\
\text { permission for } \\
\text { disclosing location }\end{array}$ & $\begin{array}{l}\text { neutral emotional } \\
\text { attitude-give } \\
\text { habitual } \\
\text { permission for } \\
\text { disclosing location }\end{array}$ & $\begin{array}{l}\text { negative attitude, } \\
\text { anxiety, concerns } \\
\text { about privacy; } \\
\text { refuse location } \\
\text { disclosure }\end{array}$ \\
\hline Reflection & $\begin{array}{l}\text { unique perception of digital divide; } \\
\text { unique language used in describing } \\
\text { photos; views on digital/material } \\
\text { boundary; articulated individual } \\
\text { views on technology } \\
\text { (questions 3-5,15-16) }\end{array}$ & $\begin{array}{l}\text { either positive or } \\
\text { negative critical } \\
\text { reflection }\end{array}$ & $\mathrm{N} / \mathrm{A}$ & lack of reflection \\
\hline
\end{tabular}




\section{Results}

Our coding scheme allowed for 48 possible attitude types-including those formed by N/A codes. Of these, 22 were identified in the survey results and a further 4 were excluded from the analysis because they were represented by only a single occurrence. This gave us 18 attitude types (Table 2)—which covers all possible options without N/A. It can be seen that, in general, positive and neutral attitudes toward LBS are dominant (Figure 3), with the three most frequent types that constitute almost half (48.6) of all types being marked as positive in the emotional dimension-which relates to RQ2. It is worth noting that the same types have a very low level of knowledge of the technological workings and mechanism of location-based services (LBS) and the data grabbing practices (RQ1). This also corresponds with the lack of reflection (Figure 4). The majority of the answers from people belonging to this group paint a picture of technology being perceived as an almost invisible part of everyday life. No second thought is given to the possible negative consequences and dangers of disclosing one's location. What can be seen as surprising is the fact that the most frequent attitude type that has a negative emotional attitude is also very similar regarding its lack of reflection (Figure 4). Those people fear LBS, but this has nothing to do with any kind of deeper understanding or a higher level of knowledge. When we compare people who show a high amount of reflection (Figure 5) with those that do not (Figure 4), it seems that to possess reflection one must also have at least some degree of knowledge. There is a strong positive and statistically significant correlation between knowledge and reflection. Deeper reflection cannot, however, be associated with negative emotions. Those with the most polarized views on the subject of LBS were almost equally distributed between positive and negative attitudes.

Table 2. Attitude types used in the analysis.

\begin{tabular}{|c|c|c|c|c|}
\hline Knowledge & Emotions & Reflection & Frequency [\%] & Cum. Sum [\%] \\
\hline $\mathrm{N}$ & $\mathrm{Y}$ & $\mathrm{N}$ & 20.7 & 20.7 \\
\hline $\mathrm{N}$ & 0 & $\mathrm{~N}$ & 18.2 & 38.9 \\
\hline 0 & $\mathrm{Y}$ & $\mathrm{N}$ & 9.6 & 48.6 \\
\hline $\mathrm{N}$ & $\mathrm{N}$ & $\mathrm{N}$ & 7.1 & 55.7 \\
\hline $\mathrm{Y}$ & $\mathrm{Y}$ & $\mathrm{N}$ & 7.1 & 62.9 \\
\hline $\mathrm{Y}$ & $\mathrm{Y}$ & $\mathrm{Y}$ & 5.4 & 68.2 \\
\hline $\mathrm{N}$ & $\mathrm{Y}$ & $\mathrm{Y}$ & 4.3 & 72.5 \\
\hline 0 & $\mathrm{Y}$ & $\mathrm{Y}$ & 3.9 & 76.4 \\
\hline $\mathrm{N}$ & 0 & $\mathrm{Y}$ & 2.9 & 79.3 \\
\hline $\mathrm{Y}$ & $\mathrm{N}$ & $\mathrm{N}$ & 2.9 & 82.1 \\
\hline 0 & 0 & $\mathrm{~N}$ & 2.5 & 84.6 \\
\hline 0 & $\mathrm{~N}$ & $\mathrm{~N}$ & 2.5 & 87.1 \\
\hline $\mathrm{Y}$ & 0 & $\mathrm{~N}$ & 2.5 & 89.6 \\
\hline 0 & $\mathrm{~N}$ & $\mathrm{Y}$ & 1.8 & 91.4 \\
\hline 0 & 0 & $\mathrm{Y}$ & 1.4 & 92.9 \\
\hline $\mathrm{Y}$ & 0 & $\mathrm{Y}$ & 1.4 & 94.3 \\
\hline $\mathrm{Y}$ & $\mathrm{N}$ & $\mathrm{Y}$ & 1.4 & 95.7 \\
\hline $\mathrm{N}$ & $\mathrm{N}$ & $\mathrm{Y}$ & 1.1 & 96.8 \\
\hline \multicolumn{5}{|c|}{ all other types-single occurrence or not present } \\
\hline
\end{tabular}




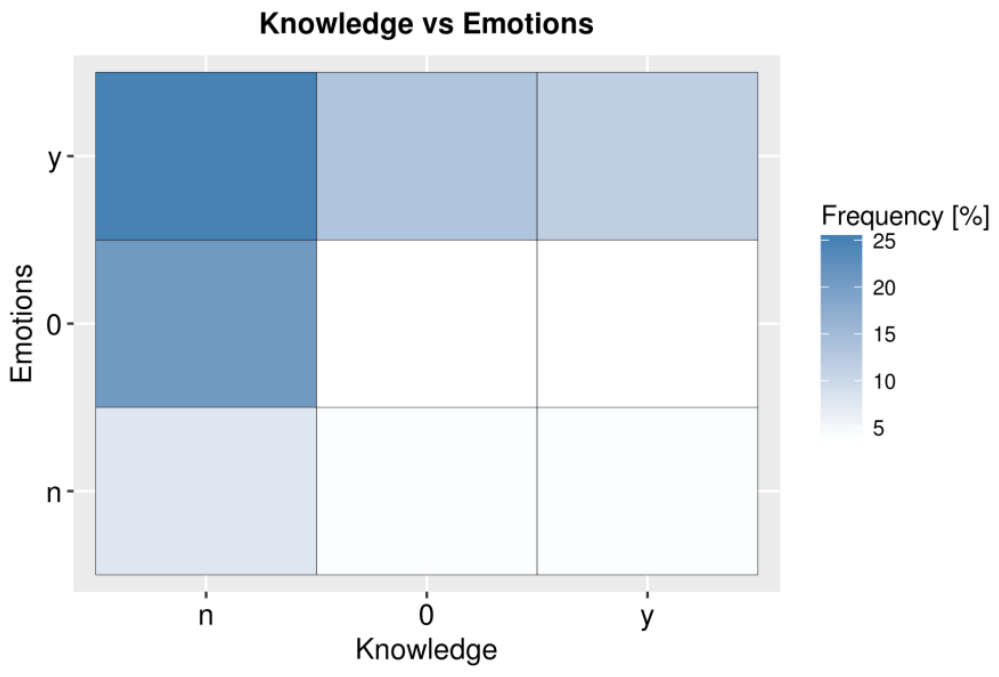

Figure 3. Frequency of responses compared between the knowledge and emotions dimensions-all users.

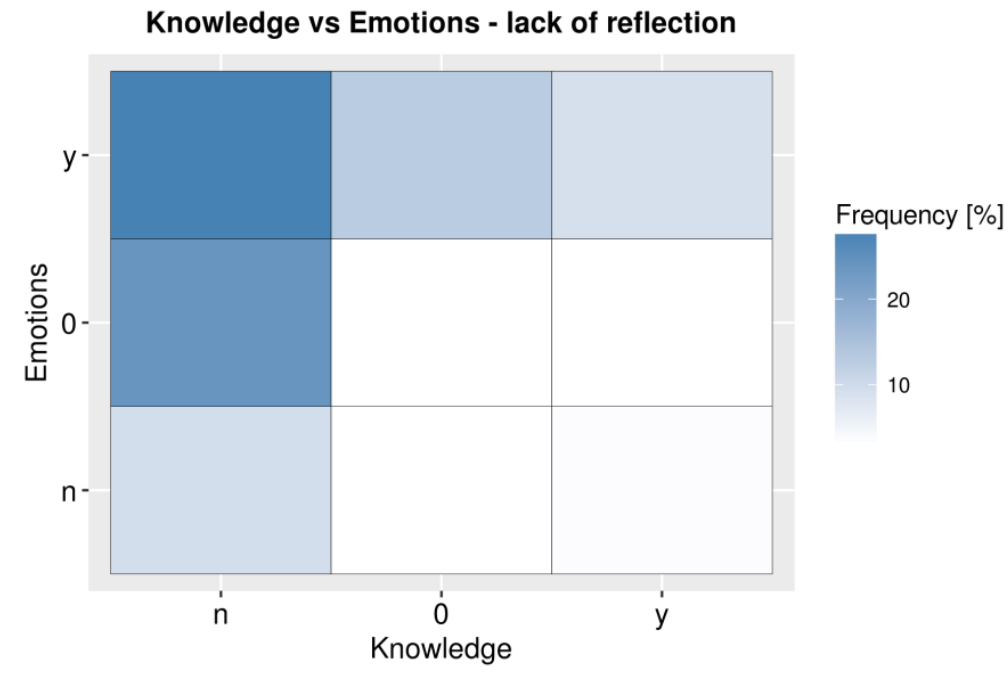

Figure 4. Frequency of responses compared between the knowledge and emotions dimensions-users without reflection $(\mathrm{N})$.

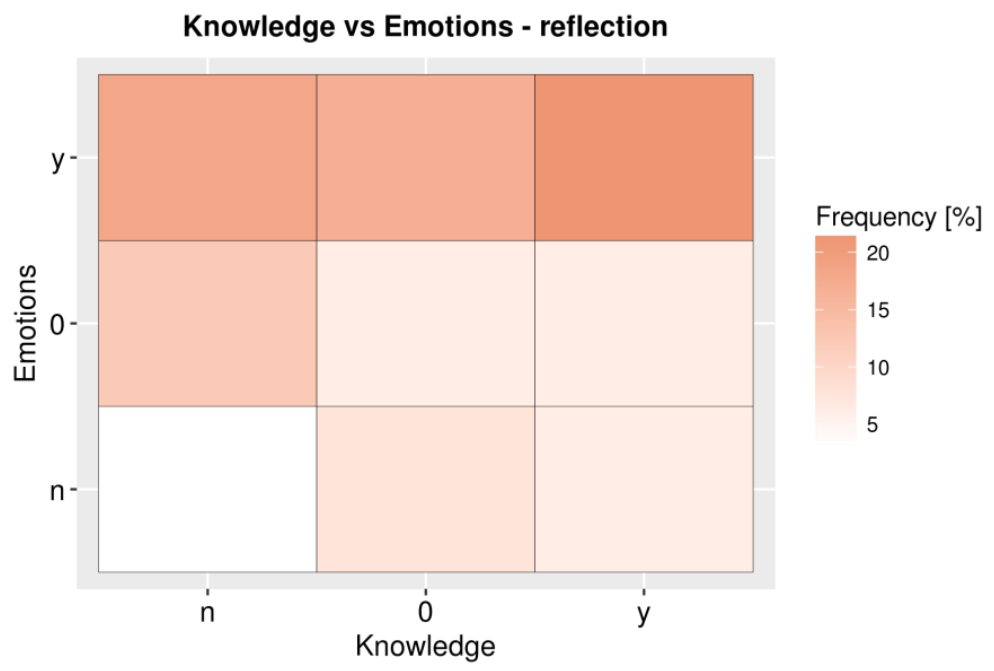

Figure 5. Frequency of responses compared between the knowledge and emotions dimensions-users with reflection $(\mathrm{Y})$. 
Our next step was to aggregate attitude types into more general themes that could more clearly describe tendencies seen in our data and answer the RQ3. Our procedure resulted in five themes that were characterized by common similarities and differences between the types that we used to form them. The main two axes that separate our themes are position in respect to knowledge and emotion dimensions and the amount of geolocated content that is being produced by people belonging to a given group. Our aim was to construct themes that would cover as many potential attitudes as possible. We did not use any weights that were dependent on type frequency. This would not have been practical because of the nature of the data we had gathered-qualitative survey design prohibits this and the sample was not representative. The resulting themes can be described as follows:

- POP-UTILITY (Figure 6) - this theme describes attitudes that are positive and enthusiastic toward LBS. People belonging to attitude types that form this theme have very little general technological knowledge and know almost nothing about the role of location in mobile services or of the data grab phenomenon. They do not care about the consequences or dangers of sharing personal location. In their view, technology brings only advancement and utility and they do not see reasons to reflect on the subject. Opinions expressed are stereotypical—e.g., associating digital exclusion with older and poor people. They happily use and frequently produce geolocated social media content whenever possible.

- PROGRAMMABILITY (Figure 7)-this theme is dominated by a neutral emotional attitude. Similar to pop-utility, people in this group do not fear the consequences of disclosing location but at the same time they much more rarely feel the need to use this possibility. They perceive LBS as just another technological innovation that they have at their disposal-a tool not a toy. They do not play with geolocated content in social media. If they use LBS, it is for a very specific, down-to-earth purpose, e.g., navigation. They do not reflect on the role of location data grab and they possess very little knowledge about technology. Not surprisingly, they almost never consciously produce geolocated content.

- HEART and MIND (Figure 8) - in this theme we grouped people who show a positive emotional attitude but also possess a much higher level of knowledge than the previous two themes. They also much more often reflect on the role of location-based services in the society. This reflection can be described as cautiously optimistic with location technology being perceived as problematic but rather promising. This point of view does not lead them, however, to participate in geolocated content production.

- AGENCY (Figure 9) - in this case, the production of content forms the main axis around which this theme is created. People in this theme have a predominantly positive emotional attitude and a mixed but mainly high level of knowledge. They have a good understanding of the mechanism of location-based services and use it for their own specific purposes. This theme is markedly different from Programmability because there is an emotional aspect involved in the equation-the connection with LBS. These services and applications perform a very important role in the quotidian activities of these people. They have the knowledge to use LBS for their own goals and they feel that they have everything under control. Reflection is present, although not in all attitude types that form this theme, and it is not associated with a particular emotional attitude.

- PRIVACY (Figure 10)—this theme is drastically different from the other four because it consists solely of attitudes that are emotionally negative toward LBS (Figure 10). People in this theme do not consciously produce geolocated media content and they actively opt out from services that allow or require personal location sharing. They also fear what can be done with data they unwillingly provide. This anxiety is mainly associated with the lack of knowledge about the technical workings of location services and the business practices of their creators and providers. However, in this theme we also find people who do have moderate or even advanced technical knowledge. People who use geolocation APIs (application programming interfaces-such as Google Maps API) in their everyday life and have firsthand experience with GIS (geographic 
information systems) can also belong in this group. If they have a negative attitude, it is motivated by their experiences with data grab practices.

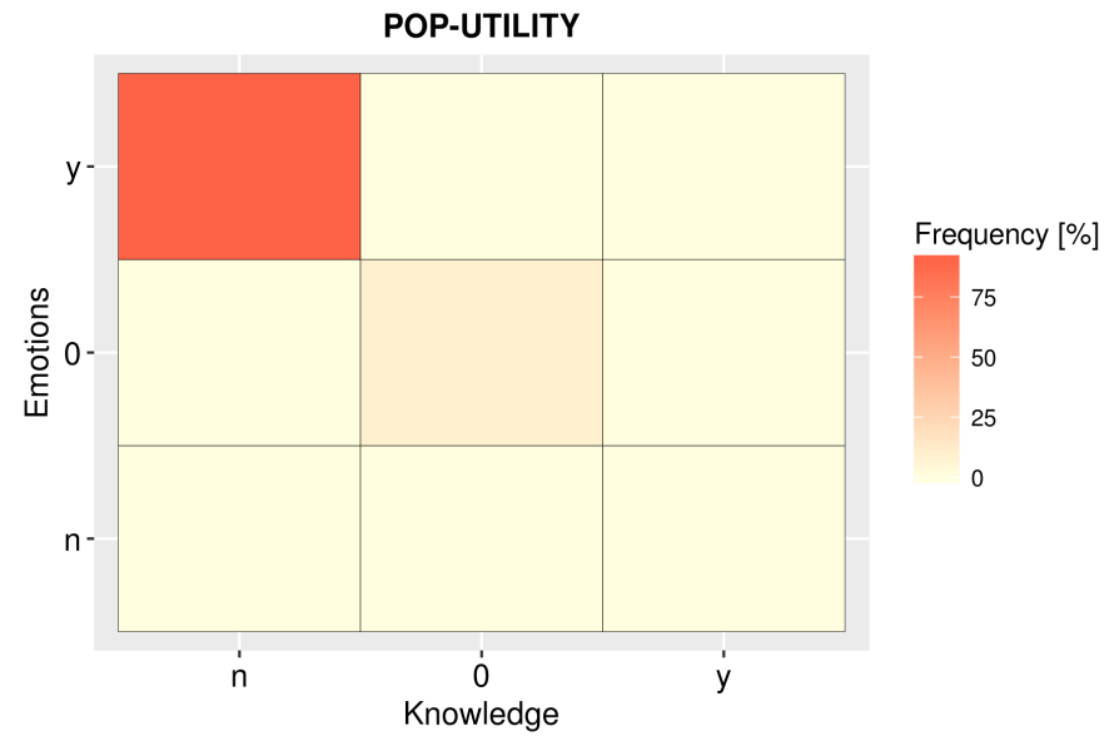

Figure 6. Frequency of responses compared between the knowledge and emotions dimensions-pop-utility theme.

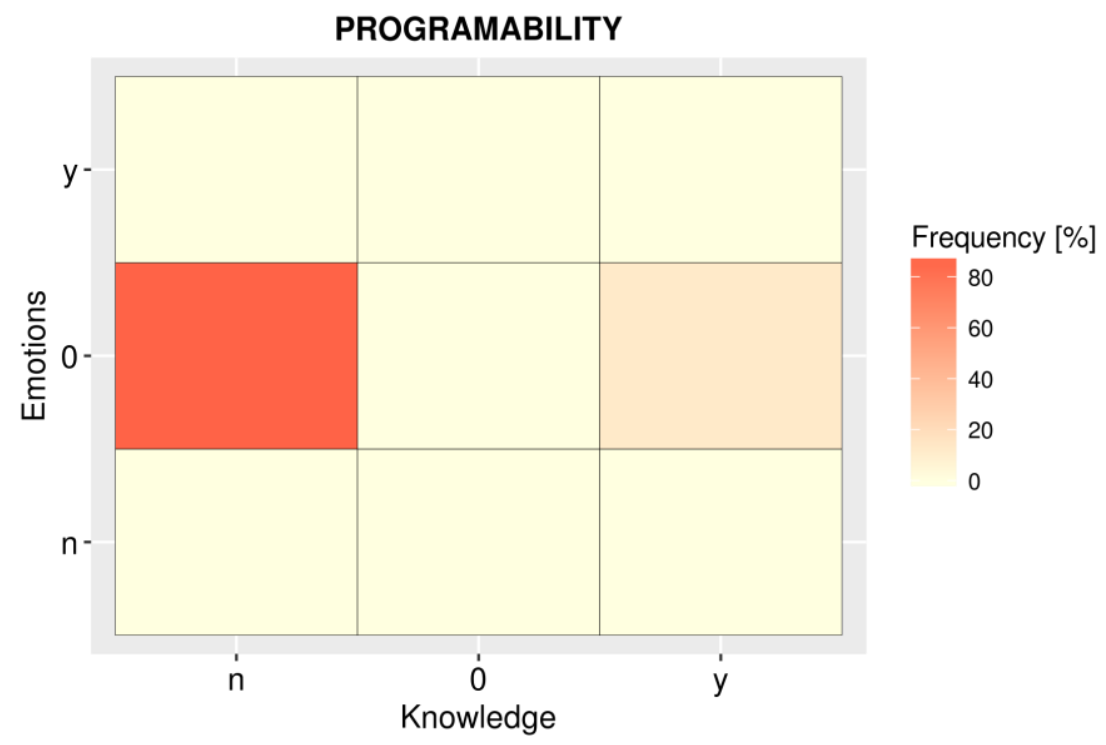

Figure 7. Frequency of responses compared between the knowledge and emotions dimensions-programmability theme. 


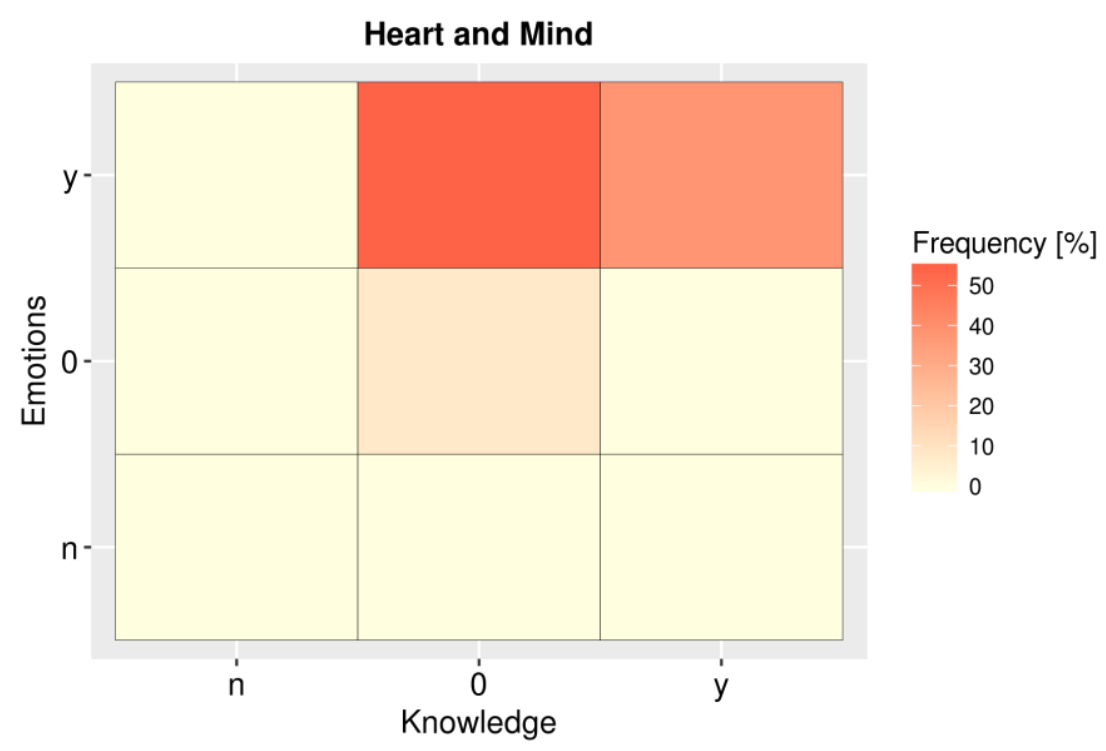

Figure 8. Frequency of responses compared between the knowledge and emotions dimensions-heart and mind theme.

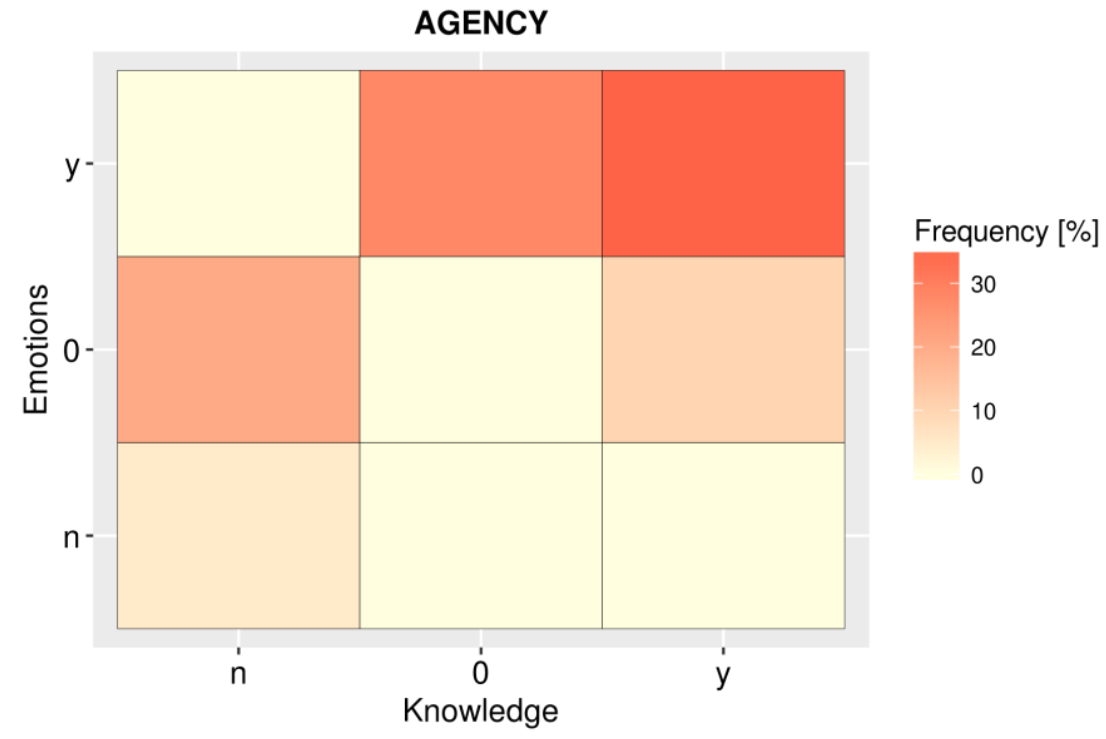

Figure 9. Frequency of responses compared between the knowledge and emotions dimensions-agency theme.

These five themes can be considered to provide an almost complete set of possible attitudes toward LBS. Although we admit the shortcomings of our sample-its low representativeness with a bias toward younger people-we think at the same time that it is sufficient for our aims. We did not find significant gender differences in our results. The part of the sample that was from Edinburgh showed similar trends and frequencies of types but we found only 15 of the most popular-this is related to our exclusion of single occurrences and the much smaller number of respondents. A surprising difference we found between Edinburgh and Poznan was that in the former, a significantly lower number of people were able to state their phone model. This could mean that they did not care as much as their Polish counterparts-technology had become less visible and more ingrained in their life. 


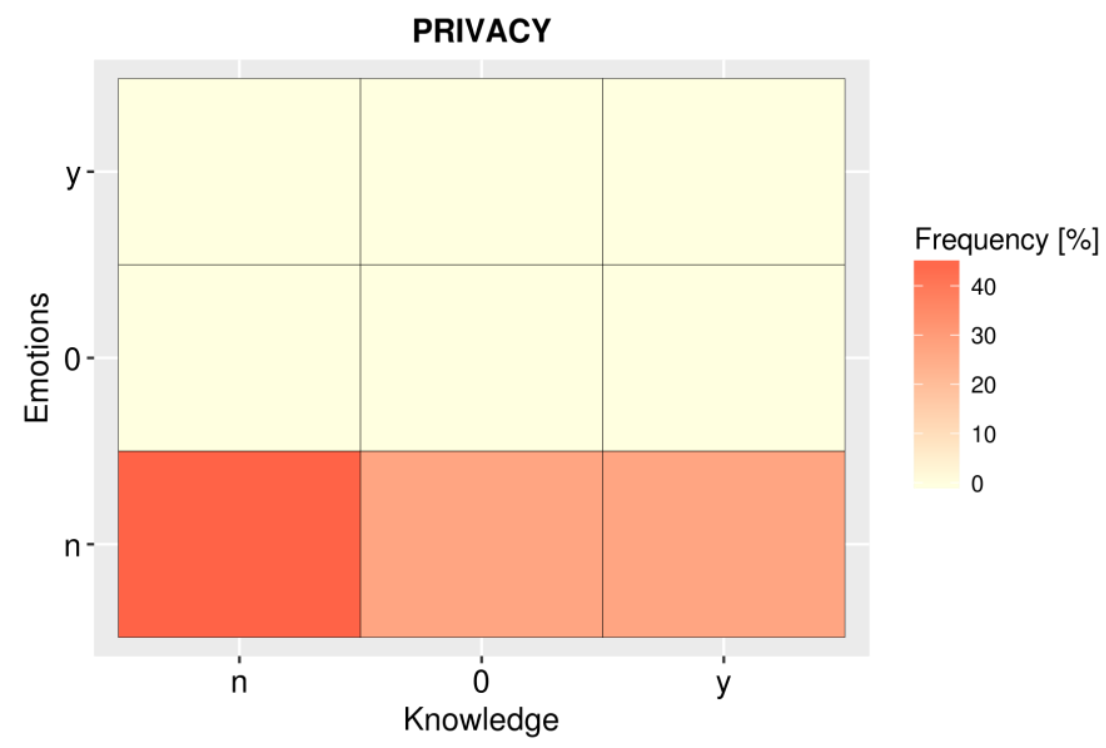

Figure 10. Frequency of responses compared between the knowledge and emotions dimensions-privacy theme.

\section{Conclusions and Discussion}

Our analysis shows that there is a wide array of attitudes adopted by people in response to the emergence of what can be described as a location-based culture that is created by the easily accessible location data and LBS that take advantage of this situation (RQ3). In this digitally augmented environment, we are constantly forced to make decisions on what to do with our location data and, at the same, we are constantly fed location data that is generated by others. Each mobile device user has, therefore, potentially two roles to fulfill—consumer and producer. The balance between the two and whether either of these roles will be adopted depends largely on an individual's attitude. The themes that we have identified in this study are mainly created by the differences in the amount of production of geolocated content, while at the same time consumption is present in every one of them. Even people who are very concerned about their location privacy have no such reservation when it comes to using services based on the information provided by others. There is little reflection on this in our respondents' answers. However, differences emerge in the way location data and services are used and these correspond to anxiety level. While people who are very concerned about privacy issues still use LBS, they do it rarely and more consciously. Among the majority of people who declared the almost daily use of LBS, there is also a divide between those who see this as a tool that is used for a specific purpose and those who use it playfully, without thinking. This divide can be seen as a much deeper chasm separating two perceptions of the relation between space/place and the digital (in the broadest sense). From this point of view, the first group sees LBS as a vehicle for changing the material world while for the second group, LBS are an inseparable part of the world. In this second group, the people from our pop-utility and heart and mind themes, we can see "players" [63] who are playing the game of a digitally augmented reality.

On the production side of the equation, the differences are much more pronounced while still being created by the same driving forces-anxiety and perception of space/place. Fear of the data grab and LBS, when it is present, leads to a complete withdrawal from the production of geolocated content. This is exemplified most clearly by the people in the privacy theme. However, even when people do not openly declare their anxiety, they are still reluctant to create geolocated content. This behavior is seen in the heart and mind and programmability themes in which people declare that they do not see the need to create such content. It seems that there are two driving forces for producers. The first one-present in the pop-utility theme-is the allure of play, when everything is done for fun, sharing of location is natural, and the consequences are far away and seen as insignificant. The second one is 
agency-when there is a specific purpose for location sharing, which can often be associated with an attempt to increase individual social capital, a mechanism described by Evans [64] using examples from Foursquare. However, apart from being a consumer or producer, there is also a third role that is not so obvious and rarely advertised by LBS providers-we are the source of the data and subjects of the data grab. Surprisingly, only in the pop-utility theme does there seem to be a large level of ignorance of this phenomenon (RQ1). And apart from the privacy theme, the common feeling is that there is nothing an individual can do to prevent this.

The prevailing attitude toward LBS and data grab seems to be neutral, with a strong undertone of resignation (RQ2). This neutrality stems from the point of view that there is no direct viable opt-out option from the digital realities of the modern world and surrendering personal locational information is just a new form of digital currency-and one that is readily available. Indirectly, this view is also present in the responses to our questions regarding the digital divide and exclusion. People who had some reflections on the subject often described the digital divide not as exclusion from ICT and mobile services but rather as separation from the "real world" caused by the constant use and reliance on digital technologies. A smaller number of people had stronger, emotional views, either very positive or negative, based on uncritical technological enthusiasm or fear of privacy violations. Such a wide spectrum of attitudes is not only produced by interaction with technology but can also be viewed as a result of different perceptions of the relation between space/place and the digital. This relation is an unavoidable condition of modern life and influences people's behavior and choices in everyday life and their attitude toward LBS and data grab is just one of these.

Ultimately, our analysis shows only the array of possibilities. Due to the nature of our research design, we cannot provide an empirical basis upon which to draw a conclusion on the prevalence of any given attitude. To do this, we designed another set of quantitative surveys and experiments that are currently being processed and the results will be published as part of our ongoing project. In addition, we think that the events of 2018 - specifically Mark Zuckerberg's testimony before the US Senate Commission and the introduction of the European GDPR directive-will inevitably change the landscape of attitudes toward LBS. This change will most likely change the balance between the themes we have identified and not their internal characteristics.

Our results can also be an indication for further research that use location data. It is now widely recognized that demographics and associated factors such as economic status and occupation can influence the quality of the data that is being grabbed-whether for commercial or scientific purposes. This fact must be taken into account in every analysis of such datasets and sound research design can limit the bias that is being introduced in this way. What we propose here is that this may simply not be enough. We have shown that among a relatively homogenous group-in regard to its demographic characteristics, there are still large differences in attitude toward using and especially producing location data. Those will invariably lead to problems with bias and quality of the data-if this dataset would be used in any kind of analysis. This issue cannot be easily amended without an in-depth understanding of the underlying social processes, and we think that more research is needed into the mechanisms of location data collection and production.

Supplementary Materials: Full questionnaire survey in English (Supplementary Materials 1) is available online at http:/ / earthisflat.net/cyberscape/supplementary_material1.pdf.

Author Contributions: Both authors contributed equally to this paper.

Funding: This work was supported by the Polish National Science Center (Grant Number UMO-2015/17/D/HS4/00272).

Acknowledgments: We would like to thank Adrian Favero for his help with conducting the survey in Edinburgh.

Conflicts of Interest: The authors declare no conflict of interest. 


\section{References}

1. Goodchild, M.F. Citizens as sensors: The world of volunteered geography. GeoJournal 2007, 69, $211-221$. [CrossRef]

2. Sui, D. The wikification of GIS and its consequences: Or Angelina Jolie's new tattoo and the future of GIS. Comput. Environ. Urban Syst. 2008, 32, 1-5. [CrossRef]

3. Crampton, J.W. Cartographic Rationality and the Politics of Geosurveillance and Security. Cartogr. Geogr. Inf. Sci. 2003, 30, 135-148. [CrossRef]

4. Crampton, J.W. The biopolitical justification for geosurveillance. Geogr. Rev. 2007, 97, 389-403. [CrossRef]

5. Fisher, P.F.; Dobson, J.E. Who Knows Where You Are, and Who Should, in the Era of Mobile Geography? Geography 2003, 88, 331-337.

6. Dobson, J.E.; Fisher, P.F. Geoslavery. IEEE Technol. Soc. Mag. 2003, 22, 47-52. [CrossRef]

7. Marwick, A.E.; Boyd, D. Networked privacy: How teenagers negotiate context in social media. New Media Soc. 2014, 16, 1051-1067. [CrossRef]

8. Abbas, R. The social implications of location-based services: An observational study of users. J. Locat. Based Serv. 2011, 5, 156-181. [CrossRef]

9. Ricker, B.; Schuurman, N.; Kessler, F. Implications of smartphone usage on privacy and spatial cognition: Academic literature and public perceptions. GeoJournal 2015, 80, 637-652. [CrossRef]

10. Swanlund, D.; Schuurman, N. Mechanism Matters: Data Production for Geosurveillance. Ann. Am. Assoc. Geogr. 2016, 106, 1063-1078. [CrossRef]

11. Bhuiyan, J.; Warzel, C. “God View”: Uber Investigates Its Top New York Executive for Privacy Violations. Available online: https://www.buzzfeed.com/johanabhuiyan/uber-is-investigating-its-top-new-yorkexecutive-for-privacy (accessed on 10 July 2018).

12. DeGroot, J.M.; Vik, T.A. "We were not prepared to tell people yet": Confidentiality breaches and boundary turbulence on Facebook. Comput. Hum. Behav. 2017, 70, 351-359. [CrossRef]

13. Shiode, N.; Li, C.; Batty, M.; Longley, P.A.; Maguire, D. The Impact and Penetration of Location-Based Services; CASA Working Paper Series 50; Centre for Advanced Spatial Analysis (UCL): London, UK, 2002; pp. 1-16.

14. Pew Research Center Unlike Other Mobile Activities, Location-Based Services Appeal to Smartphone Owners of All Ages; Pew Research Center: Washington, DC, USA, 2016.

15. Raper, J.; Gartner, G.; Karimi, H.; Rizos, C. A critical evaluation of location based services and their potential. J. Locat. Based Serv. 2007, 1, 5-45. [CrossRef]

16. Huang, H.; Gartner, G. Current Trends and Challenges in Location-Based Services. ISPRS Int. J. Geo-Inf. 2018, 7, 199. [CrossRef]

17. Perusco, L.; Michael, K. Control, trust, privacy, and security: Evaluating location-based services. IEEE Technol. Soc. Mag. 2007, 26, 4-16. [CrossRef]

18. Michael, G.E.K.; Michael, M.G. The social and behavioural implications of location-based services. J. Locat. Based Serv. 2011, 5, 121-137. [CrossRef]

19. Dearman, D.; Hawkey, K.; Inkpen, K.M. Rendezvousing with location-aware devices: Enhancing social coordination. Interact. Comput. 2005, 17, 542-566. [CrossRef]

20. Evans, L. Location-based services: Transformation of the experience of space. J. Locat. Based Serv. 2011, 5, 242-260. [CrossRef]

21. Clarke, R. Information technology and dataveillance. Commun. ACM 1988, 31, 498-512. [CrossRef]

22. Michael, M.G.; Michael, K. Toward a state of überveillance [special section introduction]. IEEE Technol. Soc. Mag. 2010, 29, 9-16. [CrossRef]

23. Michael, K.; Clarke, R. Location and tracking of mobile devices: Überveillance stalks the streets. Comput. Law Secur. Rev. 2013, 29, 216-228. [CrossRef]

24. Clarke, R.; Wigan, M. You are where you've been: The privacy implications of location and tracking technologies. J. Locat. Based Serv. 2011, 5, 138-155. [CrossRef]

25. Michael, K.; McNamee, A.; Michael, M.G. The emerging ethics of humancentric GPS tracking and monitoring. In Proceedings of the International Conference on Mobile Business (ICMB'06), Copenhagen, Denmark, 26-27 June 2006; p. 34.

26. Abbas, R.; Michael, K.; Michael, M.G. The regulatory considerations and ethical dilemmas of location-based services (LBS): A literature review. Inf. Technol. People 2014, 27, 2-20. [CrossRef] 
27. Thatcher, J. You are where you go, the commodification of daily life through 'location'. Environ. Plan. A 2017, 49, 2702-2717. [CrossRef]

28. Boyd, D.; Crawford, K. Critical questions for big data: Provocations for a cultural, technological, and scholarly phenomenon. Inf. Commun. Soc. 2012, 15, 662-679. [CrossRef]

29. Rose-Redwood, R.S. Governmentality, Geography, and the Geo-Coded World. Prog. Hum. Geogr. 2006, 30, 469-486. [CrossRef]

30. Elwood, S.; Leszczynski, A. Privacy, reconsidered: New representations, data practices, and the geoweb. Geoforum 2011, 42, 6-15. [CrossRef]

31. Kar, B.; Crowsey, R.C.; Zale, J.J. The myth of location privacy in the United States: Surveyed attitude versus current practices. Prof. Geogr. 2013, 65, 47-64. [CrossRef]

32. Abdelmoty, A.I.; Alrayes, F. Towards Understanding Location Privacy Awareness on Geo-Social Networks. ISPRS Int. J. Geo-Inf. 2017, 6, 109. [CrossRef]

33. Prudham, S. Commodification. In A Companion to Environmental Geography; Castree, N., Demeritt, D., Liverman, D., Rhoades, B., Eds.; Wiley-Blackwell: Hoboken, NJ, USA, 2009; pp. 123-142.

34. Pickles, J. Ground Truth: The Social Implications of Geographic Information Systems; Guilford Press: New York, NY, USA, 1995.

35. Pickles, J. A History of Spaces: Cartographic Reason, Mapping, and the Geo-Coded World; Routledge: London, UK; New York, NY, USA, 2004; ISBN 0-415-14497-3.

36. Crampton, J.W.; Krygier, J. An introduction to critical cartography. ACME Int. J. Crit. Geogr. 2005, 4, 11-33.

37. Crampton, J.W. Cartography: Maps 2.0. Prog. Hum. Geogr. 2009, 33, 91-100. [CrossRef]

38. Crampton, J.W. Mapping: A Critical Introduction to Cartography and GIS; Blackwell Companions to the Ancient World; Wiley-Blackwell: Malden, MA, USA, 2010; ISBN 978-1-4051-2172-9.

39. Elwood, S. Straddling the fence: Critical GIS and the geoweb. Prog. Hum. Geogr. 2014, 1, 5.

40. Pavlovskaya, M. Digital Place-Making: Insights from Critical Cartography and GIS. In The Digital Arts and Humanities; Springer Geography; Springer: Cham, Switzerland, 2016; pp. 153-167, ISBN 978-3-319-40951-1.

41. Rzeszewski, M. Geosocial capta in geographical research-A critical analysis. Cartogr. Geogr. Inf. Sci. 2018, 18-30. [CrossRef]

42. Graham, M.; Zook, M.; Boulton, A. Augmented reality in urban places: Contested content and the duplicity of code: Augmented reality in urban places. Trans. Inst. Br. Geogr. 2013, 38, 464-479. [CrossRef]

43. Kaplan, D. What Snap's Acquisition of Placed Says about the Value of Location Tech. Geomarketing. 2017. Available online: https:/ / geomarketing.com/what-snaps-acquisition-of-placed-says-about-the-value-oflocation-tech (accessed on 10 July 2018).

44. Thatcher, J.; O'Sullivan, D.; Mahmoudi, D. Data colonialism through accumulation by dispossession: New metaphors for daily data. Environ. Plan. Soc. Space 2016, 34, 990-1006. [CrossRef]

45. Lin, J.; Amini, S.; Hong, J.I.; Sadeh, N.; Lindqvist, J.; Zhang, J. Expectation and purpose: Understanding users' mental models of mobile app privacy through crowdsourcing. In Proceedings of the 2012 ACM Conference on Ubiquitous Computing, Pittsburgh, PA, USA, 5-8 September 2012; ACM: New York, NY, USA, 2012; pp. 501-510.

46. Przybylski, A.K.; Murayama, K.; DeHaan, C.R.; Gladwell, V. Motivational, emotional, and behavioral correlates of fear of missing out. Comput. Hum. Behav. 2013, 29, 1841-1848. [CrossRef]

47. Foucault, M. Discipline and Punish; Vintage: New York, NY, USA, 1977; Volume 191.

48. Dobson, J.E.; Fisher, P.F. The Panopticon's Changing Geography. Geogr. Rev. 2007, 97, 307-323. [CrossRef]

49. Fraser, A. Land grab/data grab. Program. City Work. Pap. 2017, 31, 1-32.

50. Poikela, M.; Toch, E. Understanding the Valuation of Location Privacy: A Crowdsourcing-Based Approach. In Proceedings of the 50th Hawaii International Conference on System Sciences 2017, Waikoloa, HI, USA, 4-7 January 2017.

51. Kitchin, R.; Dodge, M. Code/Space: Software and Everyday Life; Software Studies; MIT Press: Cambridge, MA, USA, 2011; ISBN 978-0-262-04248-2.

52. Thrift, N. Remembering the Technological Unconscious by Foregrounding Knowledges of Position. Environ. Plan. D 2004, 22, 175-190. [CrossRef]

53. Kaasinen, E. User needs for location-aware mobile services. Pers. Ubiquitous Comput. 2003, 7, 70-79. [CrossRef] 
54. Pratkanis, A.R.; Breckler, S.J.; Greenwald, A.G. Attitude Structure and Function; Psychology Press: New York, NY, USA; London, UK, 2014.

55. Krech, D.; Crutchfield, R.S.; Ballachey, E.L. Individual in Society: A Textbook of Social Psychology; McGraw-Hill: New York, NY, USA, 1962.

56. Crawford, K. The Anxieties of Big Data. New Inq. 2014, 30. Available online: https://thenewinquiry.com/ the-anxieties-of-big-data / (accessed on 10 July 2018).

57. Leszczynski, A. Spatial big data and anxieties of control. Environ. Plan. D 2015, 33, 965-984. [CrossRef]

58. Dear, M. The postmodern challenge: Reconstructing human geography. Trans. Inst. Br. Geogr. 1988, $262-274$. [CrossRef]

59. Jałowiecki, B. Innowacje w naukach społecznych. Stud. Socjol. 1992, 3-4, 126-127.

60. Sagan, I. Metodologiczne dylematy wspólczesnej geografii społeczno-ekonomicznej. Stud. Reg. Lokal. 2000, 2, 5-19.

61. Gravetter, F.J.; Forzano, L.-A.B. Research Methods for the Behavioral Sciences; Cengage Learning: Boston, MA, USA, 2018.

62. Jansen, H. The Logic of Qualitative Survey Research and its Position in the Field of Social Research Methods. Forum Qual. Sozialforschung Forum Qual. Soc. Res. 2010, 11. [CrossRef]

63. Saker, M.; Evans, L. Everyday life and locative play: An exploration of Foursquare and playful engagements with space and place. Media Cult. Soc. 2016, 38, 1169-1183. [CrossRef]

64. Evans, L. Locative Social Media; Palgrave Mcmilan: London, UK, 2015.

(C) 2018 by the authors. Licensee MDPI, Basel, Switzerland. This article is an open access article distributed under the terms and conditions of the Creative Commons Attribution (CC BY) license (http://creativecommons.org/licenses/by/4.0/). 